\title{
Para una historia de la difusa arquitectura moderna en Chile
}

\author{
About a history of the vague modern architecture in Chile
}

<Resumen>

La ambigüedad histórica y teórica que presenta la aparición de la arquitectura moderna en nuestro país, es aquí observada desde las implicancias atribuidas a la explotación salitrera, a la formación académica de los arquitectos, a la organización gremial, a la condición telúrica del país y a las revistas de arquitectura locales.

<Abstract>

The historical and theoretical ambiguity presented by the apparition of modern architecture in our country is being observed in this article from the point of view of the implications due to nitrate exploitation, architects' academic training, syndicates' organisation, the soil condition of the country and the local architecture journals.

<PALABRAS CLAVE >

CULTURA / MODERNIDAD / EXPERIENCIA / CAMBIO / PROYECTO

-KEYWORDS>

CULTURE / MODERNITY / EXPERIENCE / CHANGE / PROJECT

\section{La cultura de la modernidad}

Uno de los aspectos más radicales de la modernidad cultural que impregna y rebasa todos los campos y a todos los protagonistas consiste en el impacto que se vive como efecto de los cambios que introduce la producción industrial en «la experiencia de lo cotidiano» ${ }^{1}$, que finalmente tocan a la economía, al régimen de trabajo y a la vida social, como asimismo al modo de hacer y concebir la ciudad, la edificación pública y doméstica. Este fenómeno se introdujo en Chile desde mediados del siglo xıx con ocasión de la explotación del salitre. La experiencia vivida por los trabajadores, por sus familias, por diversos administradores y profesionales que tuvieron participación en la gestión empresaria $y$, en general, la experiencia vivida por el país en todos los planos, independientemente de que haya sido una iniciativa extranjera, dejó una huella que no desapareció con la partida de las compañías a sus países de origen, iniciando un proceso de transformación cultural moderna que ha de tenerse en cuenta como antecedente del cambio de la arquitectura que dio origen a la arquitectura moderna².

\footnotetext{
Arquitecto Universidad de Chile (1978), Doctor Arquitecto Universidad Politécnica de Madrid (2004), dedicado a la docencia e investigación desde 1983, se ha especializado en teoría e historia de la arquitectura moderna, y ha escrito artículos para revistas nacionales y extranjeras.

Humberto Giannini. La reflexión cotidiana. Hacia una arqueología de la experiencia Santago: Editorial Universitaria, 1988; pp. 15 y 16: «La experiencia a cuya realidad intentamos acercarnos (...), no puede, por principio, ser la experiencia personal de cada sujeto, en cuanto ésta es visibilidad, 'presencia ante los sentidos' o clara evocación de dicha presencia. (...) Hacia otro lado se mueve nuestra búsqueda: hacia un hipotético subsuelo de principios sumergidos en esa experiencia individual; sumergidos y que, sin embargo, echan sus raíces hasta el fondo de ella, condicionándola al punto de hacerla, a veces, incomprensible para sí misma; se mueve, en fin, hacia el subsuelo de una experiencia común. (...) Esta experiencia cuya sustancia geológica intentamos extraer se transfiere de un modo decisivo en la comunicación, en el habla. Esto es casi una tautología. Al comunicarnos verbalmente somos solidarios -en pequeña medida en el plano consciente; en una gran medida en el plano inconsciente- de una experiencia histórica y social cuyas huellas pueden ser objetivamente rastreadas en una suerte de etimología fundamental; ser rastreadas hasta el punto lejano, impreciso, tal vez, mítico, en que las palabras -y no sabríamos decir cómo- van a dar a las cosas».

2 Humberto Eliash, Manuel Moreno. Arquitectura y modernidad en Chile 1925-1965. Una realidad múltiple. Santiago: Ediciones Universidad Católica de Chile, 1989; p. 15: «Queremos entender por arquitectura moderna aquella que va surgiendo desde los procesos de modernización, en cuanto dicen relación con el desarrollo cultura y social, con los avances tecnológicos y principalmente con nuestra propia historia de la arquitectura».
} 
Este planteamiento anticipa el rastro histórico de la modernidad arquitectónica por lo menos cincuenta años, oponiéndose a la interpretación predominante sobre los comienzos de la arquitectura moderna ${ }^{3}$ que ha sobreestimado los aspectos formales, externos y estereotipados de la condición moderna ${ }^{4}$, preponderando la responsabilidad en el cambio de personas individualmente consideradas y ha devaluado la experiencia local al sostener que el origen arquitectónico moderno corresponde a una copia irreflexiva, imitación de un estilo más o una importación ${ }^{5}$, sin dejar lugar para reconocer la independencia y propiedad cultural de la gestión local, desconociendo de paso que la transferencia por imitación ha sido un paradigma de la evolución de la arquitectura de todos los tiempos, en todas las culturas.

\section{Orígenes de la arquitectura moderna en Chile}

Los orígenes de la arquitectura moderna en Chile tienen un precedente en los procesos de explotación del salitre, del cobre y del carbón durante la segunda mitad del siglo XIX cuando con capital y tecnologías extranjeras éstos se iniciaron en territorios del norte, centro y sur del país. Ingleses, alemanes y norteamericanos, además de algunos españoles, concurrieron a la explotación del salitre como luego lo hicieron con el cobre y el carbón, poniendo en evidencia la creciente necesidad de materias primas para aumentar la producción industrial en marcha en Europa y Estados Unidos desde hacía cien años por lo menos y que, al promediar el siglo $\mathrm{xIx}$, ampliaban los mercados e incorporaban nuevos centros de aprovisionamiento. De esta manera países como Chile se incorporaron a la transformación cultural, social, política y económica que como una ola venía desde su inicio europeo durante el siglo XVIII, cubriendo y arrastrando a todos los países que de una u otra manera fuesen útiles y estuviesen dispuestos a participar de este proceso históricamente llamado Revolución Industrial ${ }^{6}$.

Planos de techumbre y columnas de fierro en galería central de Palacio de Tribunales.

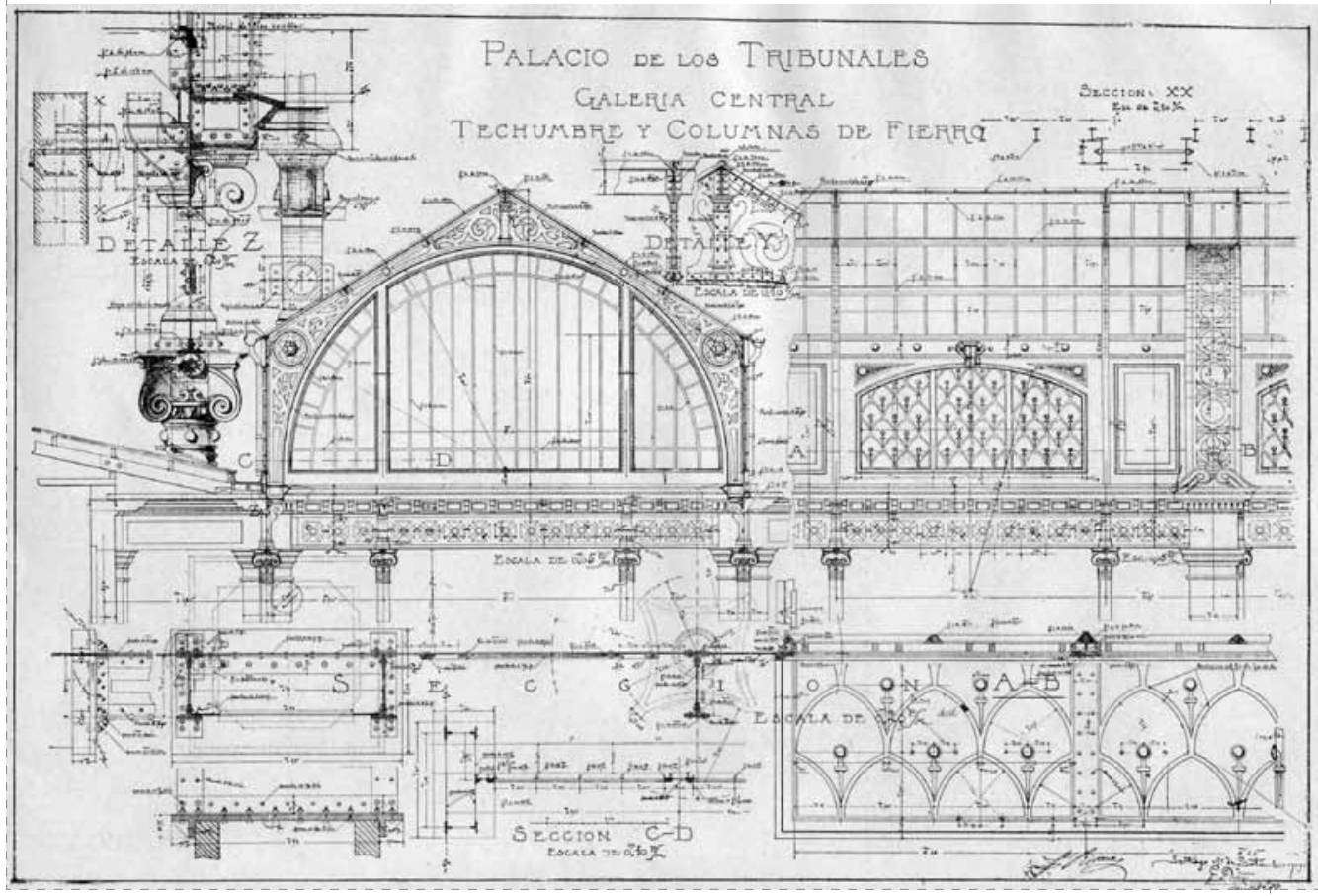

La explotación del salitre (desierto de Atacama, al norte del país, 1870) y del cobre (en Sewell, a $80 \mathrm{~km}$, al sur de Santiago en 1906 y, en Chuquicamata en la zona norte, en 1915) supuso la aplicación de un conjunto de intervenciones que por sí mismas representaron industrialización: empleo de máquinas, línea de producción, separación de operaciones, de procedimientos y de tareas racionalmente establecidas y especialmente organizadas y la participación de numerosa mano de obra en todas las faenas. Como se sabe, el salitre se hallaba en el desierto en lugares donde hasta entonces no habían existido asentamientos humanos. Por lo tanto, en este caso, las instalaciones productivas debieron estar vinculadas a asentamientos obreros creados expresamente con este fin. Miles de personas fueron contratadas en la zona sur del país, abandonando la actividad agrícola que les había sido tradicional, para trasladarse con sus familias al desierto muchos todavía eran solteros, otros estaban recién casados, aún sin hijos. Todos fueron atraídos por mejores expectativas económicas y, muchas veces, seducidos por promesas engañosas o compromisos que no se cumplieron. Dejaron su tierra, renunciaron al único trabajo que sabían hacer y protagonizaron una masiva migración asociada a una transformación radical del régimen laboral, dando origen a la primera generación proletaria del país, base de la clase obrera industrial. El resultado de este proceso de explotación minera se materializó en verdaderas ciudades industriales ${ }^{7}$, propiedad de las empresas, fundadas en torno a la producción en medio del desierto, donde no sólo se organizó el trabajo, sino también la vida social y comunitaria que allí se dio. En estos enclaves urbanos de explotación minera se aplicaron criterios de planificación

3 Eliash y Moreno. Op. cit.; p. 15: «El terremoto de Talca 1928 y los viajes de los arquitectos chilenos en la segunda mitad de los veinte, marcan el comienzo del proceso de modernidad en nuestra arquitectura».

4 Eliash y Moreno. Op. cit.; p. 15: «Es claro que la modernidad (en síntesis, la caracterización de lo moderno en la cultura) de la que estamos hablando es parte de un proceso mucho más amplio que las epidérmicas imágenes modernas con las que se confunde muchas veces».

5 Eliash y Moreno. Op. cit.; p. 11; en la presentación del libro dice Ramón Gutiérrez: «La modernidad importada que este libro analiza es en definitiva el producto de una superestructura ideológica que nos enseñó a ver nuestra realidad - de la cual forma parte indisoluble esa modernidad importada- con otros ejes (sic) que los nuestros». Eugenio Garcés F. Las ciudades del salitre. Un estudio de las Oficinas Salitreras en la Región de Antofagasta. Santiago: Editorial Universitaria, Universidad Católica del Norte, 1988. p. 17: «El marco de la Revolución Industrial es entonces el que define este proceso y lo dota de capital, tecnología y referencias arquitectónicas».

Garcés. Op. cit.; p. 15: «...este conjunto de asentamientos industriales relacionados a la extracción de materias primas, el desarrollo de una importante red ferroviaria y la construcción de ciudades portuarias, se constituye en un capítulo que pertenece con propiedad al ámbito de la Revolución Industrial...». 

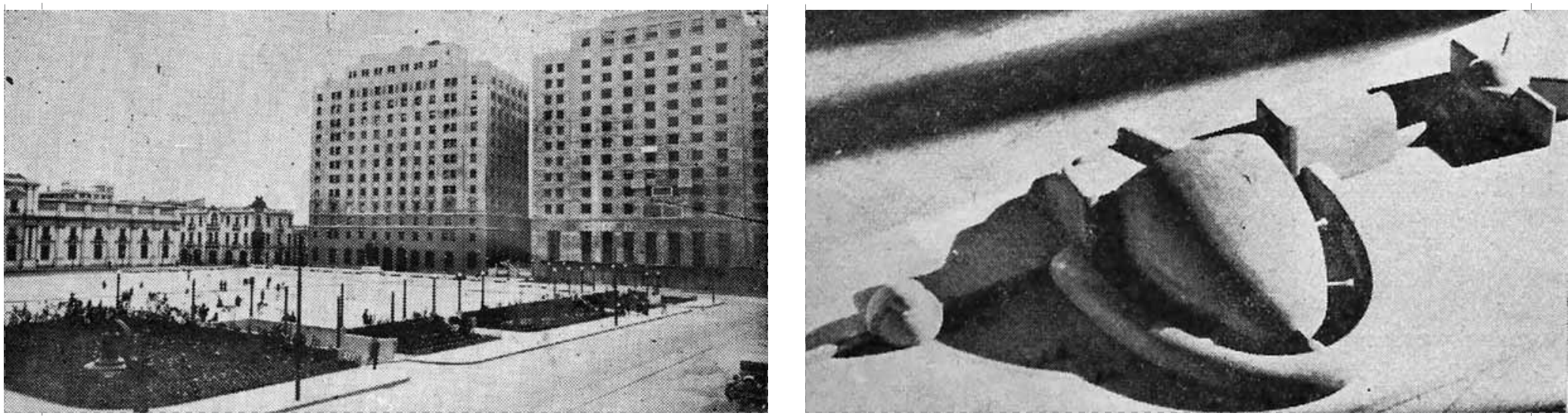

y trazado urbanístico, se dispusieron sectores de viviendas, zonas de esparcimiento, emplazamiento de edificios públicos (escuelas, iglesias, hospitales, etc.), se abrieron calles, se distribuyeron plazas, las construcciones fueron hechas conforme a planos específicos de cada construcción sin dejar nada al azar. Se emplearon materiales del lugar, tales como la tierra y la piedra, y también otros de avanzada tecnología traídos del exterior, como el acero, el hormigón armado, la plancha ondulada de acero zincado, la madera terciada, como asimismo, sistemas constructivos como el ballon frame $u$ otros en base a elementos estandarizados y de prefabricación. A todo esto se agregó la construcción de la red de ferrocarriles que, iniciada en 1856, contribuyó y sostuvo el transporte del caliche hasta los puertos de salida, junto con comunicar a los enclaves salitreros entre sí y con el resto del país.

\section{Arquitectura académica y desarrollo profesional}

En un proceso paralelo y ajeno a la explotación salitrera se llevaba a cabo el desarrollo de la arquitectura como resultado de la formación de arquitectos en las universidades. Durante la segunda mitad del siglo xIx se crearon las dos escuelas de arquitectura más antiguas del país (de la Universidad de Chile, en 1849 y de la Universidad Católica, en 1894). Desde entonces, los profesionales enfrentaron la competencia de todos aquellos que ejercían el oficio sin haber sido formados en las universidades, amparados en la experiencia de obra, la aplicación de modelos tomados de álbumes y la ausencia de una legislación que regulara el ejercicio profesional. Esta situación indujo la reacción de los arquitectos universitarios en defensa del mercado de trabajo y prontamente, también, en defensa de la calidad del servicio profesional prestado, cuando se incorporó el conocimiento de los nuevos materiales cuyo empleo exigió conoce técnicas específicas de cálculo y construcción. Conocimientos que no es posible adquirir sólo con la experiencia de obra y que su puesta en práctica mejoraba notoriamente la calidad y productividad de la construcción. A este estado de cosas se sumó que algunos arquitectos realizaron viajes a Estados Unidos y principalmente a Europa donde estudiaron, trabajaron o simplemente conocieron directamente el fenómeno de transformación de la arquitectura que se vivía en estos lugares; experiencia que trasladaron de distinta manera a su regreso a Chile, pero coincidiendo todos en que la arquitectura había dejado de ser lo que ellos habían aprendido y en la decisión de aplicar lo que habían conocido. Algunos participaron también en la reforma de la enseñanza de la arquitectura. Fue el caso de Sergio Larraín García-Moreno, Juan Martínez Gutiérrez, Roberto Dávila Carson y Rodulfo Oyarzún Philippi. Larraín García-Moreno viaja y recorre Europa; Martínez Gutiérrez, sin titularse aún, gana el concurso nacional del Pabellón de Chile en la Exposición Iberoamericana de Sevilla en 1929, permaneciendo en Europa hasta 1931; Dávila Carson estudia con Behrens, Van Tongerloo y Van Doesburg, trabaja con Le Corbusier, regresando a Chile en 1933; Oyarzún Philippi estudia en Viena y conoce al urbanista Karl Brunner, quien a instancias suyas es contratado por el gobierno de Chile, introduciendo la enseñanza de urbanismo en el país y proponiendo una reforma urbana para Santiago. Todos ellos tuvieron una destacada participación en la docencia universitaria y en los procesos de reforma de la enseñanza de la arquitectura que desde 1933 se pusieron en marcha en las escuelas del país.
Inicios de la modernidad arquitectónica

En el período que va desde mediados de siglo xIx hasta la segunda década del siglo Xx, se desarrollan los acontecimientos que dan base al nacimiento de la arquitectura moderna en Chile. Por un lado, se dio inicio a un tipo de explotación industrial de extracción de materias primas y, por otro, los arquitectos de formación universitaria reaccionaron como gremio en defensa del ejercicio profesional. Ambos hechos pertenecen al campo de la arquitectura y del urbanismo y se inscriben en el marco de los efectos de los cambios políticos, sociales y económicos que se sucedieron en el país en el mismo período, todos ellos, bajo el signo de la modernización de la cultura. Esta modernidad se hizo reconocible por las consecuencias que acarreó la incorporación de procesos industriales de producción, las aplicaciones técnicas que conllevan los avances científicos, las medidas políticas que redundan en el acrecentamiento de la participación ciudadana en el gobierno, la protección legal de los derechos civiles y de los trabajadores, el nacimiento de numerosos grupos sociales que se identifican en relación con sus fuentes de trabajo, etc. Son los efectos culturales de la hegemonía de la razón científica, desmenuzada hasta el extremo y llevada a la vida cotidiana hasta en sus más mínimas manifestaciones. Estos hechos constituyeron la base fundamental de la implantación de la arquitectura moderna en Chile. 
Ruinas del pabellón

de la Fábrica de Paños Bellavista.

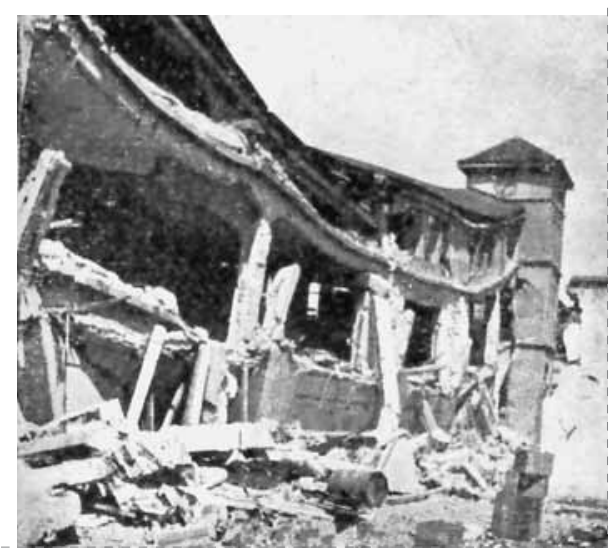

\section{El terгemoto propulsor de la modernidad}

A la voluntad humana para realizar estas iniciativas se agregó la acción de la naturaleza. Los terremotos, dadas su frecuencia y magnitud históricas en el país, han sido una condición ineludible para toda consideración de la edificación en Chile. Hubo tres en el período 1906-1939 que jugaron un papel relevante y ejercieron una enorme influencia, favoreciendo las ideas de cambio que se proponían y acelerando el proceso de modernización. El primero de la serie fue en 1906 en Valparaíso, el siguiente en Talca en 1928 y el último en Chillán en $1939^{\circ}$. El de Valparaíso puso en crisis la construcción en adobe, el de Talca impulsó la promulgación de la primera Ordenanza de Construcciones que exigió cálculo de estructuras, uso de albañilería reforzada, permisos de edificación y planes reguladores. Y en 1939, en Chillán, donde hubo alrededor de 40.000 muertos y la ciudad quedó completamente en el suelo, puso al descubierto la falta de rigor en el cumplimiento de las normas vigentes y abrió la inusual posibilidad de reconstruir totalmente la ciudad, oportunidad que coincidió con la primera generación de arquitectos titulados bajo la reforma de la enseñanza de la arquitectura. Los terremotos fueron dando la razón a los arquitectos de esa generación de la necesidad de instituir lo moderno y de llevarlo a la práctica. El desastre tuvo cierta notoriedad internacional porque atrajo el interés de Le Corbusier, quien ofreció realizar gratuitamente el plan de Chillán9. Tal generosidad tuvo su contrapartida en el debate interno que se originó entre los arquitectos locales que se dividieron entre los que apoyaban la intervención de Le Corbusier y los que la rechazaban. Entre los jóvenes titulados bajo el signo moderno de la reforma de la enseñanza se halló el apoyo a Le Corbusier, y entre los arquitectos pioneros de los viajes que los puso en contacto con la arquitectura moderna europea estuvieron los Martínez Gutiérrez. Finalmente, ganaron estos últimos; Le Corbusier no vino y la solución de reconstrucción consistió en mantener la cuadrícula fundacional y levantar edificios modernos con estructuras en hormigón armado, volúmenes de geometría pura, racionalidad funcional, economía de costos asociada a nuevas técnicas de construcción, perforación de la manzana de fachada continua y ausencia de estilos tradicionales y decoraciones historicistas.

La Asociación Gremial y las Revistas de Arquitectura en la instauración de la modernidad arquitectónica

Determinantes en la evolución de la arquitectura hacia la modernidad fueron, por una parte, la creación de la Sociedad Central de Arquitectos (1907) -que luego pasó a ser la Asociación de Arquitectos (1923)- y por otra, la publicación de revistas a cuya gestión se relacionó la organización gremial. Las revistas fueron los instrumentos que vertebraron esa evolución, cumpliendo un rol informativo y catalizador de las opiniones de los arquitectos en torno a la instauración de la modernidad arquitectónica del país. Las revistas Ilamaron la atención sobre temas eminentemente modernos: la vivienda popular, la transformación urbana y la ordenanza de construcciones y urbanización (que entre otras disposiciones reguló la obtención de permisos municipales para edificar, exigió cálculo de estructuras y estableció normas para confeccionar planos reguladores). También informaron e instruyeron sobre métodos de cálculo estructural, características de nuevos materiales y nuevas tecnologías detractores, especialmente Oyarzún Philippi y

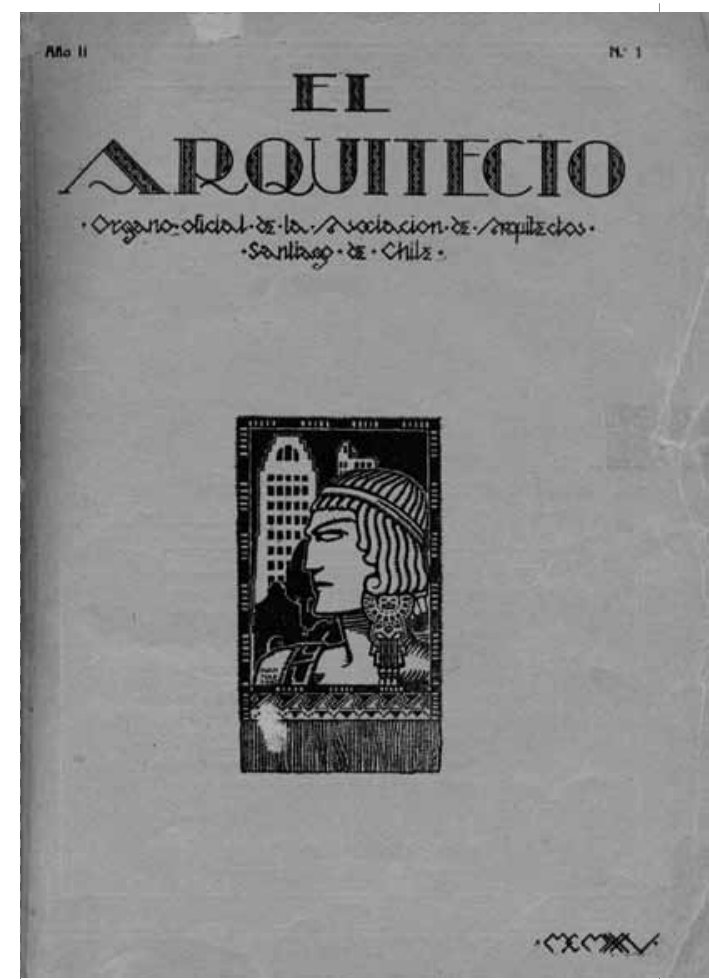

Portada de la revista El Arquitecto N 1, enero 1925
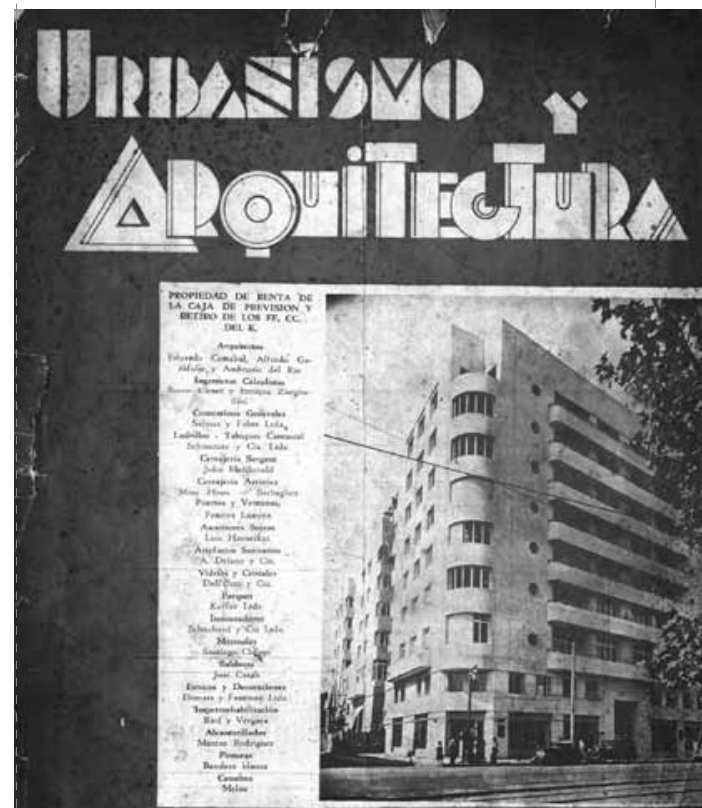

ESántiago - FEBRERO 1930 - Chllo

8 El terremoto de Valparaíso fue el 16 de agosto de 1906, el de Talca fue el $1^{\circ}$ de diciembre de 1928 y el de Chillán el 24 de enero de 1939. Además, en el mismo período, hubo un terremoto el 4 de diciembre de 1918 en Copiapó y otro, el 10 de noviembre de 1922 en Vallenar.

9 Pedro Bannen L., Fernando Pérez O., Claudio Vásquez Z. Entendidos, subentendidos y malentendidos sobre el urbanismo moderno: Alternativas del frustrado viaje de Le Corbusier a Chile. En: Massilia. Anuario de Estudios Lecorbusierianos. 2003; p. 136.
Portada de la revista Urbanismo y Arquitectura $\mathrm{N}^{\circ} 2$ 


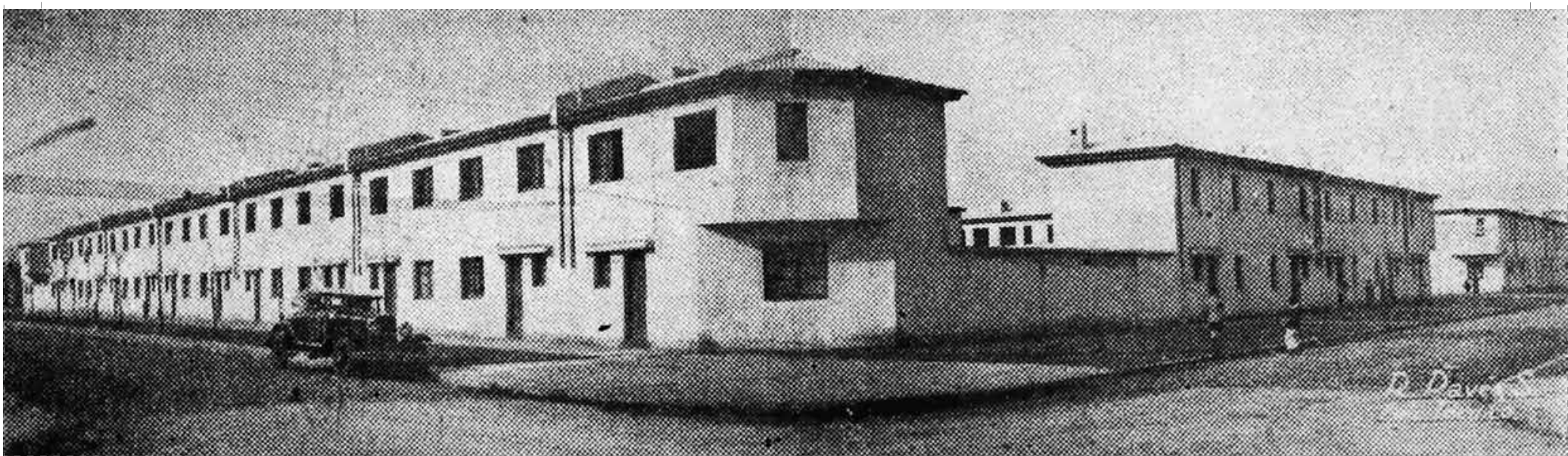

de la construcción. Movidos por el interés de proteger el ejercicio profesional, incorporar la arquitectura en el circuito de la política de Estado y la inversión inmobiliaria e impulsar la aplicación de nuevas tecnologías, los arquitectos promovieron la organización gremial que, sumada a la iniciativa de las revistas, estableció los medios con los que se realizó la conversión de la arquitectura del país a la modernidad arquitectónica en el período que va desde 1907, cuando se funda la primera organización del gremio, hasta 1942, año en que se promulgó la ley que creó el Colegio de Arquitectos de Chile. Ya en 1950 predominará en el país la arquitectura moderna y sus criterios se hallarán implantados tanto en los planes de estudio de la universidad y en las normas de administración estatal, como en la opinión pública, fenómeno observable en los medios de comunicación y en la aceptación generalizada de las propuestas arquitectónicas de nuevo cuño.

De esta manera, paralelamente, estas revistas fueron el medio por el que se agrupó a los arquitectos en torno a los intereses gremiales y difundieron el cambio de la arquitectura denominada moderna. Se integraron al cambio cultural moderno siendo ellas mismas síntoma y expresión de ese cambio. Evolucionaron con la rapidez de los acontecimientos y con ellas nació la fuerza de la difusión masiva de las ideas. Revisando su contenido se observa la capacidad que tuvieron para dar cuenta bajo distintos títulos de la evolución de los acontecimientos, parejamente con la línea editorial que mantuvieron en todas ellas, convocando a los arquitectos en torno a las preocupaciones gremiales y profesionales de las que se sintieron responsables ante la sociedad. Ellas fueron Revista de Arquitectura
(1913-1922), El Arquitecto (1924-1927), Forma (1927), Arquitectura y Arte Decorativo (1929-1931), ARQuitectura (1935-1936) y, Urbanismo y Arquitectura (1936-1941). Todas fueron publicadas en el período que va desde la fundación de la primera organización gremial en 1907, hasta la promulgación de la ley que dio origen al Colegio de Arquitectos de Chile, en 1942. Todas se crearon bajo el patrocinio o la tutela del gremio. Fueron treinta y cinco años de intensa vida gremial y de instauración de los principios de la arquitectura moderna, de los cuales, a lo menos, hay constancia de veinte años de publicación, en seis títulos y sesenta y seis ejemplares. En el período que se publicaron (1913-1941) convergió el debate de mayor intensidad y la batalla más dura para hacer prevalecer los criterios y las nuevas ideas de la modernidad arquitectónica en el ámbito político, universitario y propiamente profesional, como también ante la opinión pública. Fue una batalla cultural ligada a fenómenos de cambio de la cultura y de la sociedad, que afectaron de una u otra manera a todo el país.

\section{Los signos en las revistas} de una cultura modernizada

El crecimiento urbano, el nacimiento de la marginalidad urbana, el déficit habitacional, la incorporación de nuevas técnicas de construcción asociadas a nuevos materiales, la aparición del proletariado y la clase media burguesa, fueron notorias manifestaciones de una cultura modernizada que captaron la atención de los arquitectos, dejando constancia de ello en las revistas publicadas en el período señalado. Otras preocupaciones de índole propiamente profesional o intradisciplinar también tuvieron una expresión reiterada en las revistas, con énfasis diverso, en distintos momentos, pero manteniendo siempre presencia a lo largo del período. Fueron iniciativas que al cumplirse constituyeron conquistas profesionales en el ámbito político e institucional. La característica de todas ellas fue que consolidaron el quehacer del arquitecto y de la arquitectura en una perspectiva moderna: reforma de la enseñanza de la arquitectura e independencia de las escuelas correspondientes a las facultades de ingeniería; participación y convocatoria en concursos; promoción de la legislación del campo arquitectónico; ocupación de cargos en instituciones de crédito hipotecario; organización y participación en congresos. Este fenómeno histórico confirma la idea que la organización gremial constituyó una especie de vanguardia, que con claro objetivo delineó una serie de tareas que finalmente lograron instituir la modernidad arquitectónica en el país, más allá de todo personalismo, estableciendo estructuras de servicio o acción profesional.

Una de esas tareas fue la organización y participación en los Congresos Panamericanos de Arquitectos. Tuvieron una influencia continental que se observa en la asistencia numerosa de delegaciones de los distintos países miembros, en los temas abordados en cada oportunidad y en los efectos producidos por las asociaciones gremiales en sus respectivos países. Impulsaron la creación de colegios profesionales, que las escuelas de arquitectura no dependieran de las Facultades de Ingeniería, apoyaron las reformas universitarias de la enseñanza de la arquitectura ${ }^{10}$ y promovieron las Ordenanzas Generales de Construcciones y Urbanización. 
La modernidad arquitectónica como modo de pensar el proyecto

La arquitectura moderna se identifica con el cambio radical en la manera de concebir el proyecto a partir del siglo xx. Este fenómeno comenzó a surgir en el mundo durante el siglo xIx, principalmente con la incorporación de criterios de decisión fundados en nuevos materiales, en las técnicas asociadas a su aplicación, en la producción industrial y en la estandarización de la construcción que hicieron abandonar los estilos, los ornamentos historicistas y la belleza, hasta entonces, bases tradicionales de la arquitectura. Estos aspectos incidieron al interior de la disciplina e indujeron nuevos principios con los que pensar el proyecto. A esto se sumó el impacto de los cambios sociales, políticos y económicos en el ámbito de la arquitectura, que hicieron emerger nuevos requerimientos tales como la transformación urbana y la vivienda económica. De esta manera, la arquitectura moderna se estableció como nuevo marco de realización de la arquitectura a contar del siglo pasado ${ }^{11}$.

La historia de la evolución de la arquitectura que cambió hasta hacerse moderna es un proceso que dondequiera que haya ocurrido estará ligado a la comprensión de la arquitectura de hoy en ese lugar. Esta relación de la arquitectura contemporánea con su precedente original moderno le confiere particular interés al estudio de ese nacimiento. Este interés aumenta si se tiene en cuenta que en Europa, considerado el lugar donde por primera vez surgió la arquitectura moderna, el fenómeno estuvo vinculado a procesos que no se dieron en otras regiones, tales como la industrialización de la producción, la incorporación masiva de la máquina como recurso principal de ese proceso y los cambios políticos, económicos y sociales que, en conjunto, crearon las condiciones para que surgiera una arquitectura nueva. Nueva por sus recursos materiales, por los criterios de decisión proyectual y por sus respuestas formales. En el caso de Chile, la industrialización estuvo presente a través de las compañías extranjeras que explotaron los recursos mineros y no fue parte de un proceso de desarrollo interno.

Edificio de una Caja de Previsión de Empleados Bancarios.

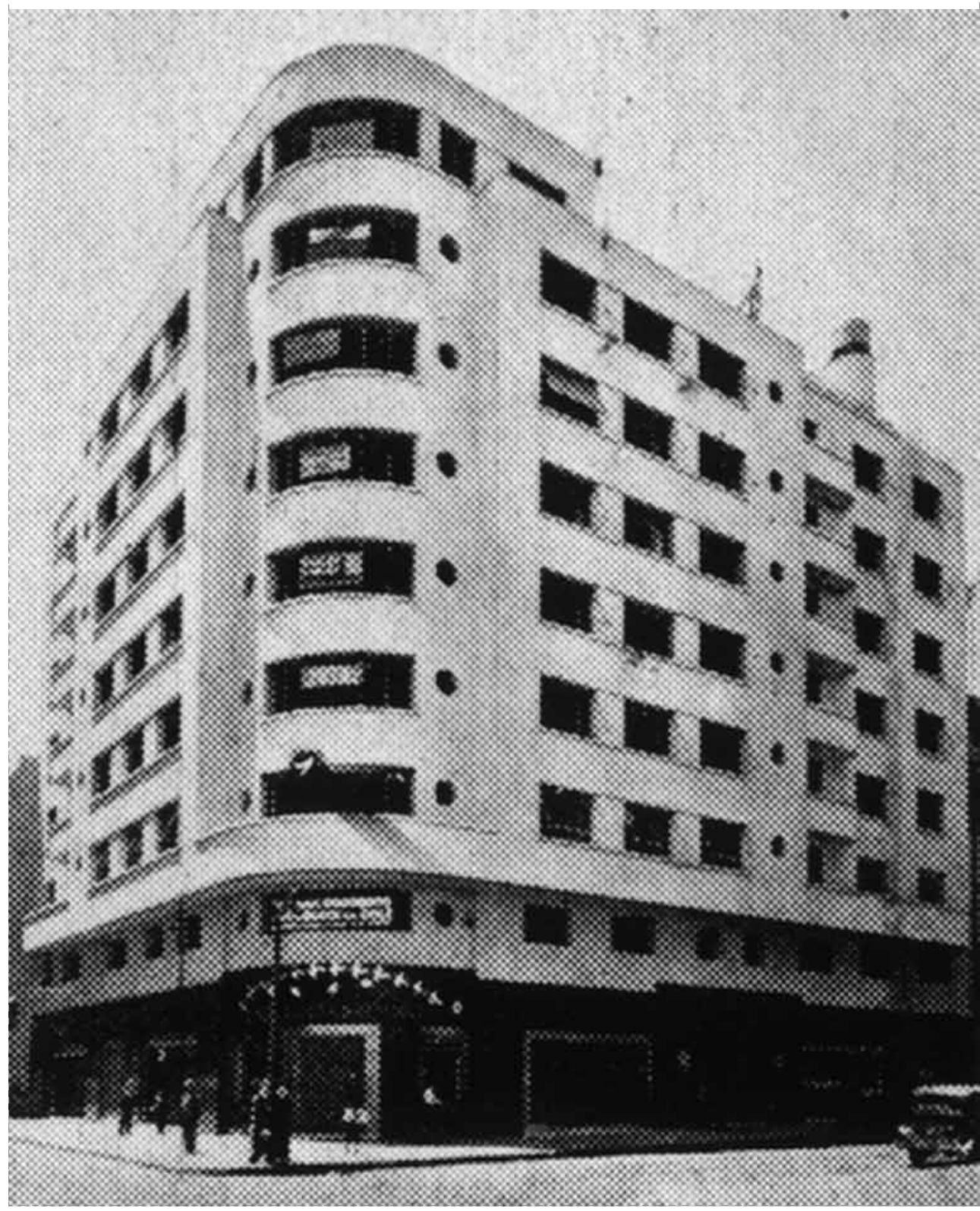

Esta explicación resume en una interpretación teórica los hechos históricos con que la arquitectura moderna, de muy diversas maneras, surgió en distintos países e instauró el precedente de toda arquitectura posterior ${ }^{12}$. Por esto, contribuir a la comprensión de la evolución que ha seguido la arquitectura del país hasta hoy constituye un motivo de investigación que sigue abierto y, en ese contexto, adquiere especial interés conocer los hechos históricos que dieron origen a la arquitectura moderna local.

10 En 1927 se consideró una conquista la integración de la Escuela de Arquitectura de la Universidad de Chile a una Facultad de Ingeniería y Arquitectura (ver Revista Forma 1927; 2: p. 40). Más tarde, en 1939, se luchó por la creación de la Facultad de Arquitectura (ver Revista Urbanismo y Arquitectura 1939; 2: p. 81). La Universidad de Chile tuvo su primera reforma en 1933, y luego otra en 1946; la Universidad Católica la realizó en 1948.

Eliash y Moreno. Op. cit.; p. 26: «...La historia oficial ha consignado solamente lo que los textos de arquitectura internacional han definido como arquitectura moderna para explicar este siglo».

12 La historia canónica de la arquitectura moderna quedó establecida, principalmente, por los trabajos de N. Pevsner (1936), S. Giedion (1941), B. Zevi (1950), L. Benevolo (1960). Más tarde se sumaron los trabajos de R. Banham (1960), R. de Fusco (1975), M. Tafuri y F. Dal Co (1977), K. Frampton (1980). 